\title{
The Role of Diaspora in Disseminating Indigenous Knowledge Entrepreneurship
}

\author{
Henrietta Onwuegbuzie \\ Lead Faculty, Entrepreneurship, Lagos Business School, Pan-Atlantic University, Lagos, Nigeria
}

\begin{abstract}
2017 Research Leap/Inovatus Services Ltd. All rights reserved.

DOI: $10.18775 /$ jibrm.1849-8558.2015.24.3003 URL: http://dx.doi.org/10.18775/jibrm.1849$\underline{8558.2015 .24 .3003}$

\section{Keywords}

Indigenous knowledge, Diaspora communities Indigenous solutions, Rural policy, Culture, Sustainability

Indigenous Knowledge has proven to be very useful in solving many problems faced in modern society; yet, this body of knowledge is under-recognised, and consequently fastdisappearing. This paper presents an objective review of indigenous knowledge amidst the practices of modern society. It begins by providing a detailed exegesis of the concept of indigenous knowledge. It further builds on this base in making comparisons between the qualities and features of indigenous solutions, and those from modern-day technology. With quick examples, these comparisons show the relative advantages of each one, with special attention to many dimensions in which indigenous solutions excel modern solutions. The underlying principles that make indigenous knowledge so valuable are also discussed with a view to eliciting best practices for immediate use (especially by practitioners, policy makers, and development workers) in the modern society. Finally, in order to spread the benefits and increase the imprints of indigenous knowledge, propositions are made on the roles of diaspora communities in preserving and propagating indigenous solutions, especially the ones native to them.
\end{abstract}

\section{Introduction}

Little attention has been paid to the relevance and importance of indigenous knowledge for solving many problems faced in modern society. For decades, indigenous people have generated solutions that are sometimes even more effective than mainstream solutions (Srinivas \& Sutz, 2008), using their indigenous knowledge. This is because indigenous people usually have an intimate knowledge of the ecosystem in their locality and through accumulated experience, have learned to manage them in a sustainable way. Indigenous knowledge solutions, therefore, tend to be sustainable, because the resources are readily available; environmentally-friendly, because they are keenly aware of the need to preserve the environment which sustains them; and cost-effective, because the inputs are both effective and usually not expensive.

As pointed out in the declaration at the 1999 United Nations Educational, Scientific, and Cultural Organisation (UNESCO) world conference on science and the use of scientific knowledge: Traditional societies, many of them with strong cultural roots, have nurtured and refined systems of knowledge of their own. Special action must be taken to conserve and cultivate this fragile and diverse world heritage, in the face of globalization and the growing dominance of a single view of the natural world as espoused by science (Paragraph 36: Declaration at UNESCO World Conference on Science and the use of Scientific Knowledge and the Science Agenda-Framework for Action, Budapest, 1999).

The above underscores the importance of indigenous knowledge. Overlooking these various forms of knowledge, which abound in all countries, will imply ignoring useful information from the indigenous knowledge that is relevant to contemporary society. This paper therefore espouses and encourages the appreciation of other unpopular forms of knowledge and practices, which are quite distinct from the more common Western forms.

Some examples of indigenous knowledge solutions which are low-cost and sometimes more effective than modern day technology include; ways in which indigenous people conserve potable water in arid, drought-prone areas (Srinivas \& Sutz, 2008), unique environmentally friendly solutions developed by farmers for controlling pests as well as diseases in crops and livestock (Grenier, 1998), and their ways of conserving aquatic and terrestrial biodiversity as well as soil conservation (Gupta, 1995).

Besides the application of indigenous knowledge in the communities in which they originate, diaspora communities have the potential to advance the use of and transmission of these valuable indigenous knowledge solutions by introducing these solutions in their destination countries for the benefit of those who need them. A good example is the case of an Asian family of Indian origin migrated to the UK. One of the children had a skin eczema that resisted all prescribed treatments in the UK. When they went back to India on holiday and used an indigenous herbal preparation, eczema had gone in a matter of days. Similarly, quite a number of Nigerian families in the UK and the US, fall back on the use of indigenous "black soap" imported from Nigeria to treat skin conditions caused by a change in weather in their destination countries. These skin conditions usually fail to respond to emollients found in their destination countries, 
but easily yield to indigenous treatments from Nigeria like Shea butter or "black soap" made from palm kernel. Most affected individuals, therefore, tend to find ways to get indigenous solutions from their homelands that efficiently solve these problems. Diaspora communities have thus been noted to contribute to the development and wellbeing of the diaspora itself and their homeland in various ways including political and economic (Mohan \& Zack-Williams, 2002).

Indigenous people who possess indigenous knowledge are often found in rural areas, however there other indigenous people who possess valuable indigenous knowledge who are embedded in urban and even international contexts. Their embeddedness in these contexts, therefore, allow these entrepreneurs to combine the benefits of valuable indigenous knowledge and the resources and technology that abound in the urban/international context to scale up and disseminate valuable indigenous knowledge (Ovadje, Ayemoba, \& Thompson, 2006; Terjesen, 2007).

This paper is divided into three main sections. The first section provides a good understanding of indigenous knowledge and compares it with mainstream knowledge. This is followed by a discussion on the role of the diaspora in the utilization and transmission of valuable indigenous knowledge. Finally, the paper concludes by highlighting the importance of the valuable information and principles contained in the indigenous knowledge that is relevant to today's society and distils the implications for scholars, practitioners and development workers.

\section{Indigenous Knowledge}

Indigenous knowledge (IK), has been defined in different ways (Sen, 2005). It is however commonly considered as a local knowledge that is original to (or attributable to) a given culture, community, or group, and which is a suitable reference for decision making within the community (Grenier, 1998; Sen, 2005; Subba Rao, 2006; Warren \& Rajasekaran, 1993).

Indigenous Knowledge comprises insights, skills, and experiences of indigenous people, which has been useful over the years towards maintaining and improving their livelihood (Subba Rao, 2006: 224). It originates from trial and error rather than theory and tends to be retained within particular communities because it is deeply embedded in the culture of the community in which it originates (Emeagwali, 2003; Gupta, 2001a; Sen, 2005; Subba Rao, 2006). There are thus some areas of intersection between indigenous knowledge and mainstream science as both involve experimentation through trial and error (Emeagwali, 2003).

Indigenous knowledge is thus considered as "a systematic body of knowledge acquired by local people through the accumulation of experiences, informal experiments and an intimate understanding of the environment in a given culture" (Warren \& Rajasekaran, 1993). It is not restricted to rural dwellers as it is present in all communities that have built a body of knowledge over generations (Subba Rao, 2006).

For the purpose of this study, and similar to the previous explanations in this section, indigenous knowledge is simply defined as the body of local knowledge, that is both unique and traditional, and that exists within or is developed around the specific conditions of men and women who are natives of a particular geographic region (Grenier, 1998: 1).

While indigenous knowledge exists globally, it is strongly informed by the cultures of the communities and regions in which it exists and is thus a heterogeneous phenomenon (Mgbeoji, 2007; Purcell, 1998; Sillitoe, 1998). Sillitoe (1998) contends that the heterogeneous nature of indigenous knowledge may indeed make it difficult to provide a single universal paradigm for it. Consequently, it has been a challenge to develop an integrated theory regarding IK because IK tends to be culturally contingent rather than universally neutral (Sillitoe, 1998), as explained in the following excerpt: "Given the multitudinous nature and diversity of indigenous knowledge systems, it becomes intellectually risky, if not fraudulent for general claims to be made regarding the nature of indigenous knowledge systems.” (Mgbeoji, 2007: 77).

Though all members of a community possess IK, the quality and quantity of this knowledge varies among members of a community depending on factors: age, gender, education, daily experiences, profession, social and economic status, aptitude and intellectual capability, observation skills, roles and responsibilities to the community, outside influences, level of curiosity, mobility, and degree of control over natural resources (Grenier, 1998: 2)

Indigenous knowledge tends to be rooted in the communities in which they originate and are hardly diffused among communities (Gupta, 1995; Sen, 2005; Subba Rao, 2006), implying that there is little or no crossfertilisation of learning among communities. This challenge has led to the establishment of a number of institutions that seek to document and diffuse the knowledge of these innovations, not only among local communities but also nationally and globally (Gupta et al., 2003; Krishnan, 2005; Pathak, 2008; Subba Rao, 2006).

Indigenous knowledge is usually transmitted orally through stories, informed experiences, practical examples, and idioms with concepts that are not easily codifiable (Sen, 2005) or captured in writing or ways that are easily understood by scientists (Emery, 1997; Sillitoe, 1998). Consequently, Sillitoe (1998), points out that the restrictions of a literate intellectual tradition pose a challenge for outsiders such as researchers to understand and pass on information about Indigenous knowledge as illustrated in the following statement:

It is necessary to abandon the assumption that we can record and document indigenous knowledge and pass it "up" to interested parties as technological packages are passed "down" to beneficiaries (McCall, 1995). The dynamism of indigenous knowledge not only increases the difficulties that we face in attempting to grasp it (Cox et al., 1995) but also compromises our attempt to represent it. We have to consider how it changes when it is taken from its local cultural context and enters into the discourse of scientists, political decision-makers, and development workers. (Sillitoe, 1998: 230).

Consequently, in seeking to understand indigenous knowledge, it must be understood that IK is strongly conditioned by the culture in which it resides. Sillitoe (1998), further explains how this alternative system of learning is transmitted through generations in spite of not being written. He states that:

... we constrain understanding in reducing everything to words. People transfer much knowledge between generations by tradition learned and communicated through practical experience, and are not familiar with trying to express everything they know in words. Heirs to effective systems of natural resource exploitation that have evolved over many generations of experimentation, local farmers may follow practices that have agro-ecological implications, sometimes apparently without any need of analytical discourse (Moore and Gooledge, 1976). Knowledge is passed on by informed experience and practical demonstration; more often than it is shown or articulated. It is as much a skill as a concept (Sillitoe, 1998: 229). 
Thus experience, relationships, and oral discourse tend to be the principle means through which IK has been transmitted through generations for centuries. Considering the absence of a formal means of indigenous knowledge transfer and that IEs use IK as a means of discovering lowcost, effective, and sustainable solutions, there is a need for empirical research on the innovation process of IEs. This should allow the benefits of IK to be more easily harnessed by modern knowledge systems.

The realization of the importance of IK has led to the steady increase in the literature on indigenous knowledge systems (Grenier, 1998; Sen, 2005; Subba Rao, 2006). Many rural communities in Africa and in many parts of the world have a sophisticated understanding of their environment and have devised mechanisms for survival as well as the conservation and sustainability of natural resources (Grenier, 1998; Sen, 2005; Subba Rao, 2006; Warren \& Rajasekaran, 1993). In spite of lacking formal education, indigenous populations have continuously found solutions to their problems and a means of survival without having recourse to modern means which tend to be unaffordable for them. Consequently, understanding some of the solutions or innovations used by indigenous populations could provide ingenious ways of solving contemporary problems (Gupta, 2001a). For example, in designing sustainable projects and policies targeted at such rural communities, a sound indigenous knowledge of the local ecological system can contribute significantly to the implementation of such projects and policies (Lalonde, 1993)

Indigenous knowledge is a fundamental part of a country's knowledge system (Hindle \& Lansdowne, 2007; Sen, 2005; Subba Rao, 2006) and a number of authors point out that more sustainable and effective solutions are generated by building on the existing knowledge base (Grenier, 1998; Gupta, 1995; Monaghan, 2009; Sen, 2005; Subba Rao, 2006). The holistic nature of indigenous knowledge, which incorporates knowledge of the environment with culture and people, makes it a useful resource for achieving readily acceptable innovative solutions as the innovations generated using IK will tend to align with the values of the people that make up the market (Verma, Tsephal, \& Jose, 2004).

Indigenous knowledge is nevertheless faced with threatening extinction. The younger generations tend to show little interest in acquiring or transmitting indigenous knowledge, which they do not associate with much economic benefit since many indigenous entrepreneurs remain in the low-income bracket (Gupta, 2001a; Gupta et al., 2003; Lalonde, 1993; Peredo, Anderson, Galbraith, Honig, \& Dana, 2004; Warren, 1992). Rather, they tend to be more interested in modern forms of knowledge, which appear to hold greater financial rewards (Gupta et al., 2003).

The traditional holders of indigenous knowledge, therefore, tend to be older members of the community. This constitutes a threat to the evolution and sustainability of indigenous knowledge over time. According to an old African proverb, "When a knowledgeable old person dies, a whole library disappears" (Grenier, 1998: 1). This is because IK represents several generations of valuable experience and unrecorded information from indigenous communities, including insights on the management of the ecosystem and biodiversity (Warren, 1992). Empirical research on indigenous knowledge is therefore important for the preservation of this valuable source of useful information.

The need for mainstream scholars and scientists to pay attention to indigenous knowledge cannot be overemphasized. Sen (2005), contends that a truly global knowledge partnership will exist when people begin to view indigenous knowledge as important enough to learn about, such that individuals from developing countries (and the rural communities within them) are recognized as participants - users and contributors to knowledge (Sen. 2005: 375).

\section{Comparison Between Indigenous Knowledge and Mainstream Knowledge}

A number of authors have attempted to draw a distinction between indigenous knowledge (IK) and mainstream knowledge (MK), which is many times a synonym for Western-based knowledge, given its global prevalence (Gupta et al., 2003; UNESCO Report, 1999). Some authors posit that while an area of convergence is that both IK and MK undertake experimentation through trial and error (Agrawal, 1995; Emeagwali, 2003; Grenier, 1998; Lalonde, 1993), the major difference lies in the fact that indigenous knowledge has proprietary systems which are culturally contingent and therefore less transferable than mainstream knowledge, which tends to be universally neutral (Emeagwali, 2003; Grenier, 1998; Lalonde, 1993). For instance, the local organic mixtures used as pesticides in rural areas are known only to those communities and not widely. This is in sharp contrast to commercially available chemical pesticides, which though vary, tend to have certain general chemical components that are known in wider markets.

Contrary to the view of a distinction between IK and MK, Agrawal (1995), argues that the classification of knowledge as "indigenous" or "western", based on their content cannot hold because of the heterogeneity within both knowledge systems (Agrawal, 1995: 421). He contends that the claim that MK is universally valid while IK is limited by contextual issues is not legitimate, as MK is similarly a function of contextual factors. This view that both western and indigenous knowledge is contextual is shared by Monaghan (2009). Agrawal buttresses this view by pointing out that previous arguments regarding the failure of western technological solutions in developing countries have been based on the recognition that they did not acknowledge the difference in the socio-political and cultural context of the developing countries where the technological solutions were applied. Consequently, because the socio-cultural context to which the technical solutions were originally oriented was different, they were unable to achieve the desired results (Agrawal 1995: 425). Thus, while acknowledging the universal prevalence of MK, Agrawal (1995), undermines the view that any knowledge can be permanently categorized as "indigenous" or "western" and proposes that there are only different types of knowledge and all that knowledge is useful (Agrawal 1995: 433).

Agrawal's argument suggests that when knowledge initially originates from a community, it is initially applied or practiced within that community and gradually spreads to other communities until it eventually becomes adopted by the larger society and gradually becomes recognized as mainstream. Consequently, some of what we currently consider mainstream knowledge may have originated from indigenous knowledge. For instance, the use of shea butter for treatment has been prevalent in traditional African settings for decades as an indigenous knowledge solution. However, in the last few decades, the information on the usefulness of shea butter has been disseminated. It is now in high demand in wider markets across the globe and can be considered mainstream. Based on Agrawal's argument, indigenous knowledge can be understood as a knowledge that originates from indigenous communities and is predominantly applied within those communities as a means of survival and livelihood. However, it can eventually become disseminated widely enough to be considered mainstream knowledge. A good example is how indigenous people share their knowledge of using herbs with pharmaceutical companies, who eventually derive tablets, capsules, or syrups from these herbs and commercialize them globally. 
4. The Role of Diaspora Communities in Promoting Valuable Indigenous Knowledge Entrepreneurship

The meaning of diaspora has been defined in different ways using different typologies (Clifford, 1994; Mohan \& Zack-Williams, 2002; Newland \& Patrick, 2004). Central to the various definitions include; communities that are away from their homeland and may also have identities that are overlapping and multiple. "Diaspora also refers to ethnic minority groups of immigrant origin residing and acting in host countries but maintaining strong sentimental and material links with their countries of origin/homelands" (Ehrlich, 2009).

Diaspora communities are known to support the development of their homelands in the various ways. Some of the identified ways through which they support their home communities and themselves in the host countries include:

Politically: Diaspora communities often by disapproving of policies or groups in their home countries that disrupt the peace and security of the land (Newland \& Patrick, 2004; Mohan \& Zack-Williams, 2002).

Economically: Using ethnic business networks and social capital, the diaspora communities improve their businesses and the economic situation of their homeland. They often make remittances and returns that improve the inflow of foreign direct investment to the home countries (Lowell \& Gerova, 2004).

Diaspora communities also form strong development organizations that impact the social, political, and economic well-being of the homeland. These organizations could be hometown associations, ethnic associations, or professional associations (Mohan \& Zack-Williams, 2002).

Regarding their role in promoting indigenous knowledge, the diaspora can do this in two ways: either by leveraging principles from indigenous knowledge applying them to the tasks they perform in their destination countries to deliver better solutions or by supporting the dissemination and commercialization of effective indigenous solutions from their homelands, in their destination countries. For instance, a Nigerian Ph.D. candidate in Canada was inspired by her indigenous knowledge of herbal remedies, to seek anti-cancer solutions in natural weeds, while her colleagues focused on exploring traditional synthetic possibilities. Her search led her to the breakthrough discovery of a cancer killer plant (Ovadje et al., 2015). She has received some awards for her outstanding innovation (http://www.nhprs.ca/pamela-ovadje-mitacs-award/), which was inspired by her indigenous knowledge of the use of herbs for treating ailments. Consequently, people who possess indigenous knowledge but find themselves in other contexts and countries could apply this knowledge and solutions in their businesses or tasks, and as such promote the use and transmission of indigenous knowledge and solutions.

\section{Conclusion}

This paper has highlighted the importance of the valuable information contained in Indigenous knowledge and its relevance for contemporary society. It has presented various benefits derivable from exploiting indigenous knowledge and the solutions derivable from it. Further, it has also analyzed some of the challenges that hinder the exploitation of indigenous knowledge for the benefit of society and all humanity and highlights the role of diaspora communities in the exploitation and transmission of valuable indigenous knowledge.

The paper holds important implications for research and practice. For research, it highlights the benefits and needs for more indigenous knowledge research. This will allow modern society leverage and exploit valuable and relevant indigenous knowledge principles that can be applied to solving today's problems.

Implications for practice are several. The paper highlights the importance of enacting national policies that acknowledge the importance of indigenous knowledge and foster it. It also suggests that indigenous knowledge presents opportunities to provide affordable health care and other environmentally friendly solutions in different fields. Finally, it points out that indigenous knowledge can spur economic growth by providing a source of global competitive advantage. On the whole, the paper argues that the field of indigenous knowledge is a highly understudied area which holds valuable potential, and is, therefore, a useful area of study for development workers, who seek ways of achieving sustainable development, especially in developing countries.

\section{References}

- Agrawal, A. (1995), "Dismantling the divide between Indigenous and Scientific Knowledge”, Development and Change, Vol. 26 No. 1995, pp. 413-439. $\underline{\text { Crossref }}$

- Clifford, J. (1994), "Diasporas”, Cultural anthropology, Vol. 9 No. 3, pp. 302-338. Crossref

- Cochrane, F. (2007), "Civil society beyond the state: The impact of diaspora communities on peace building", Global Media Journal: Mediterranean Edition, Vol. 2 No. 2, pp. 19-29.

- Cox, P. G., Shulman, A. D., Ridge, P. E., Foale, M. A., \& Garside. A. L. (1995), "An integrative approach to system diagnosis: An invitation to the dance", Journal for Farming Systems ResearchExtension, Vol. 5 No. 2, pp. 67-83.

- Ehrlich, M. A. (2009), Encyclopedia of the Jewish diaspora: Origins, experiences, and culture, $\mathrm{ABC}-\mathrm{CLIO}$, California, CA.

- Emeagwali, G. (2003), "African indigenous knowledge systems (AIK): Implications for the curriculum”, in Falola, T. (Ed.), Ghana in Africa and the world: Essays in honor of Adu Boahen, Africa World Press, New Jersey, NJ.

- Emery, A. R. (1997), "Guidelines for Environmental Assessments and Traditional Knowledge", Centre for traditional Knowledge to the World Council of Indigenous People, Ottawa, 1 December, 2015.

- Grenier, L. (1998), "Working with Indigenous Knowledge: A guide for researchers", working paper, International Development Research Centre, Ottawa, 1 December, 2015.

- Gupta, A. (1995), "People's Knowledge for Survival: Grassroots Innovations for Sustainable Natural Resource Management”, paper presented at the IFADs International Conference on Hunger and Poverty, 16-23 November, Brussels, Belgium, available at: www.sristi.org/papers/new/People's\%20Knowledge\%20for\%20surv ival.RTF (accessed 1 December, 2015).

- Gupta, A. (2001a), "Framework for rewarding indigenous knowledge in developing countries: Value chain for grassroots innovations", working paper, World Trade Organisation Expert Committee, Geneva, 1 December, 2015.

- Gupta, A. K., Sinha, R., Koradia, D., Patel, R., Parmar, M., Rohit, P., Patel, H., Patel, K., Chand, V. S., James, T. J., Chandan, A., Patel, M., Prakash, T. N., \& Vivekanandan, P. (2003), "Mobilizing grassroots' technological innovations and traditional knowledge, values and institutions: articulating social and ethical capital", Futures, Vol. 35 No. 9, pp. 975-987. Crossref

- Hindle, K., \& Lansdowne, M. (2007), "Brave spirits on new paths: toward a globally relevant paradigm of indigenous entrepreneurship research", in Dana, L. \& Anderson, R. (Eds.), International handbook 
of indigenous entrepreneurship research, Edward Elgar Publishing, Cheltenham, UK. Crossref

- Krishnan, R. (2005)," Transforming Grassroots Innovators and Traditional Knowledge into a Formal Innovation System: A Critique of the Indian Experience", working paper, Indian Institute of Management, Bangalore.

- Lalonde, A. (1993), "African Indigenous Knowledge and its Relevance to Sustainable Development", in Inglis, J. T. (Ed.), Traditional Ecological Knowledge. The International Development Research Centre, Ottawa:

- Lowell, B. L., \& Gerova, S. G. (2004), "Diasporas and economic development: State of knowledge", Institute for the Study of International Migration, Washington DC.

- Mc Call, M. (1995), "ITK in East African farming systems", Indigenous Knowledge and Development Monitor Vol. 4 No. 1, pp. 20-22.

- Mgbeoji, I. (2007), “African Indigenous Knowledge Systems and Patents: Is the Patent System Relevant to the Native Healers of Southern Nigeria?", in Boons, E. \& Hens, L. (Eds.), Indigenous knowledge systems and sustainable development: relevance for Africa, Kamla-Raj Enterprises, New Delhi, pp. 77-91.

- Mohan, G., \& Zack-Williams, A. B. (2002), "Globalisation from below: conceptualising the role of the African diasporas in Africa's development", Review of African political economy, Vol. 29 No. 92, pp. 211-236. $\underline{\text { Crossref }}$

- Monaghan, A. (2009), "Conceptual niche management of grassroots innovation for sustainability: The case of body disposal practices in the UK", Technological Forecasting and Social Change, Vol. 76 No. 8, pp. 1026-1043. Crossref

- Moore, G. T., \& Gooledge, R. G. (1976). Environmental knowing: Theories, research, and methods, Dowden, Hutchinson and Ross, Stroudsburg.

- Newland, K., \& Patrick, E. (2004), "Beyond remittances: The role of Diaspora in poverty reduction in their countries of origin", working paper, Department of International Development, Washington DC.

- Ovadje, O., Ayemoba, R., \& Thompson, O. (2006), "Evaluation of the cost effectiveness EAT-set auto transfusion", International Review of the Armed Forces Medical Services, Vol. 79 No. 3, pp. 191-195.

- Ovadje, P., Hamm, C., \& Pandey, S. (2012), "Efficient induction of extrinsic cell death by dandelion root extract in human chronic myelomonocytic leukemia (CMML) cells", PloS one, Vol. 7 No. 2, pp. e30604. Crossref

- Ovadje, P., Roma, A., Steckle, M., Nicoletti, L., Arnason, J., \& Pandey, S. (2015), "Advances in the research and development of natural health products as main stream cancer therapeutics", Evidence-Based Complementary and Alternative Medicine, Vol. 2015. Crossref

- Pathak, R. (2008), "Grass-root creativity, innovation, entrepreneurialism and poverty reduction", International Journal of Entrepreneurship and Innovation Management, Vol. 8(1): 87-98. $\underline{\text { Crossref }}$

- Peredo, A. M., Anderson, R., B, Galbraith, C. S., Honig, B., \& Dana, L. P. (2004), "Towards a theory of indigenous entrepreneurship", International Journal of Entrepreneurship and Small Business, Vol. 1 No. 1/2, pp. 1-20. Crossref

- Purcell, T. W. (1998), "Indigenous Knowledge and Applied Anthropology: Questions of Defnition and Direction", Human Organization, Vol. 57 No. 3, pp. 258-272. $\underline{\text { Crossref }}$
- Sen, B. (2005), "Indigenous knowledge for development: Bringing research and practice together", International Information and Library Review, Vol. 37 No. 4, pp. 375-382. Crossref

- Sillitoe, P. (1998), "The development of Indigenous Knowledge", Current Anthropology, Vol. 39 No. 2, pp. 223-252. Crossref

- Srinivas, S., \& Sutz, J. (2008), "Developing countries and innovation: Searching for a new analytical approach", Technology in Society, Vol. 30 No. 2, pp. 129-140.

- Subba Rao, S. (2006), "Indigenous knowledge organization: An Indian scenario", International Journal of Information Management, Vol. 26 No. 3, pp. 224-233. Crossref

- Terjesen, S. (2007), "Building a Better Rat Trap: Technological Innovation, Human Capital, and the Irula", Entrepreneurship Theory \& Practice, Vol. 31 No. 6, pp. 953-963. Crossref

- UNESCO Report. (1999), World Conference on Science: Declaration on Science and the Use of Scientific Knowledge and the Science Agenda - Framework for Action. Paragraph 36, available at: http://www.unesco.org/new/en/natural-sciences/priorityareas/links/biodiversity/events/science-and-other-systems-ofknowledge/world-conference-on-science-budapest-1999declaration/ (assessed 1 December, 2015)

- Verma, S., Tsephal, S., \& Jose, T. (2004), "Pepsee systems: grassroots innovation under groundwater stress", Water policy, Vol. 6 No. 4, pp. 303-318.

- Warren, D. M., \& Rajasekaran, B. (1993), "Putting Local Knowledge to good Use", International Agricultural Development, Vol. 13 No. 4, pp. 8-10.

- Warren, M. (1992), "Indigenous Knowledge, Biodiversity Conservation and Development", paper presented at the International Conference on Conservation of Biodiversity in Africa: Local Initiatives and institutional Roles, 30 August - 3 September, Kenya, available at: https://searchworks.stanford.edu/view/4011194 (accessed 1 December, 2015). 